\title{
Ultrasound-guided radiofrequency ablation enhances natural killer-mediated antitumor immunity against liver cancer
}

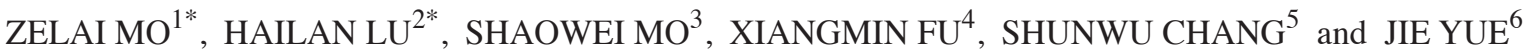 \\ ${ }^{1}$ Department of Ultrasound, The Maternal and Child Health Hospital of Hainan, Haikou, Hainan 570206; \\ Departments of ${ }^{2}$ Respiratory Medicine, ${ }^{3}$ Science and Education, ${ }^{4}$ Medical Records, ${ }^{5}$ General Surgery and \\ ${ }^{6}$ Vascular Surgery, The Hainan General Hospital, Haikou, Hainan 570311, P.R. China
}

Received May 6, 2017; Accepted November 29, 2017

DOI: $10.3892 / \mathrm{ol} .2018 .8231$

\begin{abstract}
For patients with liver cancer who are not sufficiently fit for surgical resection, radiofrequency ablation (RFA) is an effective and low risk treatment modality; however, the mechanism underlying this procedure is not fully understood. In the present study, a series of experiments were conducted, which demonstrated that RFA therapy stimulates innate antitumor immunity via directly enhancing natural killer (NK) cell cytotoxicity, thus achieving a favorable outcome for patients with liver tumors. It was determined that the percentage of NK cells within the peripheral blood of the rabbits in the RFA treatment groups were significantly higher, compared with the control groups. The levels of interferon- $\gamma$ and tumor necrosis factor- $\alpha$ in NK cells were also significantly upregulated following thermal coagulation induced via RFA. In addition, RFA enhanced the NK cell receptor, NK group 2D (NKG2D), expression and NK cell antitumor cytotoxicity in hepatic cancer cells. The results indicated that the RFA treatment could effectively eliminate liver tumors via enhancing NK-mediated antitumor activity and NKG2D expression.
\end{abstract}

\section{Introduction}

Primary liver cancer, particularly the most diagnosed subtype of hepatocellular carcinoma (HCC), is a major health problem. It is the fifth most common malignancy and the third leading cause of cancer-associated mortality worldwide (1-3). The incidence of liver cancer has significant global variations and is particularly prominent in Eastern Asia $(2,3)$. Liver cancer has had the second highest mortality rate of cancer-associated

Correspondence to: Dr Zelai Mo, Department of Ultrasound, The Maternal and Child Health Hospital of Hainan, 15 South Longkun Road, Haikou, Hainan 570206, P.R. China

E-mail: mozhelai@163.com

\section{${ }^{*}$ Contributed equally}

Key words: radiofrequency ablation, natural killer cells, liver tumor, innate immunity death in China and $17.4 \%$ of cancer deaths in Chinese adults in 2012 were from liver cancer (4). Although numerous studies have conducted research to improve the prognosis of liver cancer, run clinical studies and have achieved significant progress over the past few decades, the overall outcome of liver cancer management remains unsatisfactory, with the overall survival rate $<5$ years $(1,5)$. To date, curative resection remains the only major therapeutic method for liver cancer (1); however, there is a high frequency of postoperative recurrence $(3,6)$. Patients with liver cancer may not be eligible for resection due to complexities, including multifocal diseases, the presence of multiple tumor metastases, insufficient functional hepatic reserve or severe co-existent cirrhosis $(1,2)$. One of the major obstacles of liver cancer prognosis is metastasis, which is the leading cause of tumor mortality (7-9); therefore, for the majority of patients with primary or metastatic hepatic malignancies who are not eligible for surgical resection, the development of novel treatments is required to manage tumor growth and prevent progression.

Radiofrequency ablation (RFA) is a technology for the curative treatment of local liver cancer that has evolved during the past few decades $(10,11)$. RFA is a safe, minimally invasive, effective and repeatable modality with fewer complications than resection particularly for smaller tumors (12-14), and it has become a first-line therapy for a number of patients with non-resectable malignant cancer (15-18). The types of RFA include percutaneous RFA using ultrasound, computed tomography-guided laparoscopic RFA and laparotomy RFA (19). Ultrasound-guided laparoscopic RFA therapy, which identifies tumors and guides the placement of the RFA needle electrode via ultrasonography, have gained widespread availability and use over the past five years due to its precise targeting of the tumor (20). RFA used on hepatic tumors induces thermal coagulation necrosis of soft tissues, including partial or complete ablation of non-resectable liver lesions (19); however, the mechanism underlying the production of thermal energy used to kill the tumor cells, and whether the RFA treatment triggers any specific antitumor effects has not been fully investigated (21).

The innate and adaptive immune cells actively prevent tumorigenesis in a process termed cancer immunosurveillance (22). The innate immune system, including monocytes, macrophages, dendritic cells (DC) and natural killer (NK) cells, can directly lyse tumor cells (23). NK cells are recognized by 
their strong cytolytic activity against tumors and virus infections $(24,25)$. NK cells also regulate the innate and adaptive immune responses through cell-to-cell contact and secretion of immunoregulatory cytokines $(26,27)$. Activated NK cells promote DC cell maturation and the release of cytokines via the production of interferon (IFN)-I and tumor necrosis factor (TNF)- $\alpha$, subsequently leading to a strong stimulation of immune responses (24). In addition, mature NK cells express high levels of the NK group 2D (NKG2D) protein (28). Through recognizing ligands expressed on infected or tumor cells, NKG2D modulates lymphocyte activation and promotes the immune response, which kills the ligand-expressing cells (29-31).

RFA local to tumors has been associated with enhanced systemic antitumor T-cell immune responses (32); however, whether NK cells are involved with RFA-treated tumor cells as well as the underlying mechanism is not fully understood (33). In the present study, the effects of NK cells function and the immune state in animal models following laparoscopic RFA were investigated. The activity of NK cells from animal models following RFA administration was tested on a hepatoblastoma cell line (HepG2) and it was verified that the cellular killing ability of NK cells was able to be modulated by RFA. It was additionally demonstrated that RFA therapy directly enhances NK cell cytotoxicity via increasing NKG2D expression; therefore, the results provided novel molecular insights into the tumor suppression of immune cells during RFA-associated tumor treatment.

\section{Materials and methods}

Animal model of tumorigenesis. A total of 5 New Zealand white rabbits (3 males and 2 females, supplied by Hainan Veterans General Hospital, Haikou, China), aged between two to three months, weighing $2.5-3.0 \mathrm{~kg}$ were randomly allocated and housed with free access to water and food, with a 12:12-h day/night cycle and at a constant room temperature. Rabbits were inoculated with VX2 cells (from the Chongqing Medical University, Chongqing, China) in their hind limbs, and served as donors for liver tumor implantation and strain propagation. Briefly, lateral aspects of the hind limb of rabbits were locally shaved and disinfected using alcohol spray, following anesthetization by intravenous injection of sodium pentobarbital $(30 \mathrm{mg} / \mathrm{kg})$. A $0.5-1.0 \mathrm{ml} \mathrm{VX} 2$ tumor cell suspension, containing $1 \times 10^{6} \mathrm{VX} 2$ cells, was injected into the gluteal muscle of the hind limb of the rabbits. At two weeks after the implantation, the substantial mass was palpable in the tumor-bearing rabbits. All tumor-bearing animals were sacrificed with minimal pain and distress, and the hind limb tumors were harvested.

A total of seven New Zealand white rabbits were inoculated with VX2 tumor cells from the donor rabbits. The implantation was conducted as described previously (34). The tumor sections of 1-4 $\mathrm{mm}^{3}$, were implanted into the liver parenchyma of anesthetic recipient rabbits. The liver incision was sealed and the abdominal wall was closed, creating two layers. The animal experiments in the present study were evaluated and approved by the Institutional Animal Care and Use Committee of Research Center for Drug Safety Evaluation of Hainan (HNYWAPZX201607011).
Radiofrequency ablation. At 2 weeks following the establishment of the rabbit hepatic tumor model, RFA was applied onto prominent tumor cells of the rabbits. The liver lobe containing the VX2 tumor was explored and a single needle or a needle cluster (for larger tumors, which were $>3 \mathrm{~cm}$ ) with an internally cooled electrode was positioned to the tumor under ultrasonographic guidance. The frequency for RFA was $500 \mathrm{kHz}$ and not pulse modulated. An RF current was emitted for 12 or $15 \mathrm{~min}$ (longer time for larger tumors $>3 \mathrm{~cm}$ ) using a $200 \mathrm{~W}$ generator that delivered continuous RF energy using an automatic impedance controller. Tumor cells were heated above $50^{\circ} \mathrm{C}$ and a post-operative ultrasound was performed to identify complications, including bleeding.

Histological studies. Tumor specimens were fixed using $10 \%$ formaldehyde at $4^{\circ} \mathrm{C}$ overnight and embedded in optimal cutting temperature compound. Hematoxylin and eosin $(\mathrm{H} \& \mathrm{E})$ staining was performed at room temperature to assess the morphology of tissue sections, as described previously (35).

Flow cytometric sorting of NK cells. NK cells from the rabbit peripheral blood were blocked with $1 \%$ BSA-PBS on ice for 10 min, stained with anti-rabbit CD56 (cat. no. 3606; 1:200; Cell Signaling Technology, Inc., MA, USA), NKG2D (cat. no. ab203353; Abcam) or CD69 antibody (cat. no. ab13168; Abcam) at $4^{\circ} \mathrm{C}$ for $15 \mathrm{~min}$. The cells were then washed by $1 \mathrm{X}$ PBS three times at $4^{\circ} \mathrm{C}$ prior to being re-suspended with secondary antibody fluorescein isothiocyanate (1:500 diluted in 5\% BSA-PBS; cat. no. F2765; Invitrogen; Thermo Fisher Scientific, Inc., Waltham, MA, USA). The different cellular subsets were sorted using a FACSAria ${ }^{\mathrm{TM}}$ (BD Biosciences, Franklin Lakes, NJ, USA) cell sorter. Data was analyzed by using BD FACSDiva ${ }^{\mathrm{TM}}$ software (version 6.0; BD Biosciences).

IFN- $\gamma$ and TNF- $\alpha$ analysis. The IFN- $\gamma$ and TNF- $\alpha$ concentrations in the cell culture supernatants were determined using aduo-set ELISA kit (cat. no. H052), according to the manufacturer's instructions (Nanjing Jiancheng Bioengineering Institute, Nanjing, China).

In vitro killing assay. The killing activity of NK cells was tested via flow cytometry. Briefly, NK cells were separated using a CD56 positive selection kit (EasySep ${ }^{\mathrm{TM}}$ Human CD56 Positive Selection kit; Stemcell Technologies, Inc., Beijing, China), according to the manufacturer's protocol. The cytotoxicity assay was performed as described by the study of Hoppner et al (36). Briefly, peripheral blood mononuclear cells from VX2 tumor rabbits were incubated with selection kit and separated with magnet. NK cells remained in the tube while unwanted cells were poured off. The selected NK cells together with macrophages from VX2 tumor rabbits treated with/without RFA were used as effector cells. HepG2 human hepatoblastoma cells purchased from the Cell Bank of Shanghai Institute of Biochemistry and Cell Biology Chinese Academy of Sciences, were cultured in in RPMI-1640 medium supplemented with $10 \%$ (v/v) fetal bovine serum, $100 \mathrm{U} / \mathrm{ml}$ penicillin and $100 \mu \mathrm{g} / \mathrm{ml}$ streptomycin glutamine (all Gibco; Thermo Fisher Scientific, Inc.) and used as target cells. The effector cells were co-cultured with HepG2 cells for $4 \mathrm{~h}$ at $37^{\circ} \mathrm{C}$ in an atmosphere containing $5 \% \mathrm{CO}_{2}$, following which 
the cell mixture was stained with 7-aminoactinomycin D (7-AAD; Beckman Coulter, Inc., Brea, CA, USA) in the dark for $15 \mathrm{~min}$. Flow cytometry data were resolved using a FACSAria flow cytometer (BD Biosciences) and analyzed using FlowJo 7.2.5 software (Tree Star Inc., Ashland, OR, USA). NK cytotoxicity (\%) was calculated as the proportion of cells positive for 7-AAD.

Quantitative polymerase ( $q P C R$ ). Reverse transcription and followed by quantitative PCR was used to examine the expression level of FasL and perforin. Briefly, total RNA from rabbit blood was extracted by TRIzol ${ }^{\circledR}$ reagent (Life Technologies; Thermo Fisher Scientific, Inc.) according to the manufacturer's protocol. Total RNA (500 ng) was reversed transcribed with Superscript IV Transcriptase (Invitrogen; Thermo Fisher Scientific, Inc.) according to the manufacturer's protocol and using random primers. qPCR analyses were performed with primers for FasL and perforin with the SsoFast SYBR-Green qPCR mix (cat. no. 1725201; Bio-Rad Laboratories, Inc., Hercules, CA, USA) according to the manufacturer's protocol on an Eppendorf MasterCycler Realplex with the thermal cycling conditions were composed of an initial denaturation step at $98^{\circ} \mathrm{C}$ for $5 \mathrm{~min}$, then 45 cycles at $95^{\circ} \mathrm{C}$ for $30 \mathrm{sec}$ and $60^{\circ} \mathrm{C}$ for $30 \mathrm{sec}$. The experiments were carried out in duplicate for each data point. The relative quantification in gene expression was determined using the $2^{-\Delta \Delta \mathrm{Cq}}$ method (37).

Statistical analysis. The results are expressed as the mean \pm standard deviation from tumor cells in the control or experimental animals. For calculations using one-way analysis of variance (with Tukey's honest significant difference post hoc test), SPSS 18.0 (SPSS, Inc., Chicago, IL, USA) was used. Graphs were produced using GraphPad Prism software v6.01 (GraphPad Software, Inc., La Jolla, CA, USA). P $<0.05$ was considered to indicate a statistically significant difference.

\section{Results}

Establishment and evaluation of the VX2 liver tumor model in rabbits. The VX2 is a fast-growing adenocarcinoma cell line, which has been extensively used to study various aspects of tumor behavior (38). To establish the rabbit liver tumor model, a VX2 cell suspension was inoculated into the sub-capsule of the left anterior lobe of the rabbit liver. Then, seven rabbits that exhibited considerable tumor growth at two weeks following VX2 cell implantation were used in the present study. The tumors were round in shape and were as large as $2 \mathrm{~cm}$ in diameter, with a total weight of $5.2 \pm 2.0 \mathrm{~g}$ (Fig. 1A). Microscopic examination via H\&E staining revealed that the tumors had notable necrosis in their centers and that the cells were irregularly arranged, indicating an invasive growth capability (Fig. 1B).

Morphological changes following RFA. Next, the morphological alterations following RFA administration were further examined. Representative venous thromboses were identified in the portal or hepatic vein branches central to RFA zones (Fig. 2A). At four weeks after thermal ablation, the coagulation on the tumor gradually became white. The boundaries between the tumor cells and surrounding non-tumorous
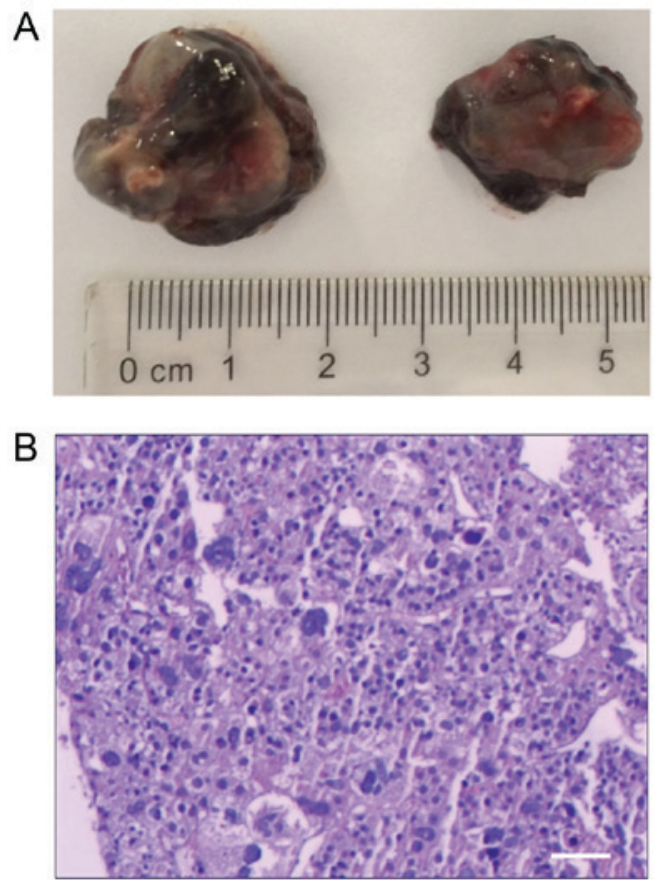

Figure 1. Establishment and evaluation of the metastasis model of VX2 tumor cell lines in rabbits. (A) Liver tumors were round in shape and contained no notable capsules. The boundaries between tumor and non-tumor tissues were clear. The cross section revealed hemorrhaging and necrosis in the center of the tumor. (B) Microscopy indicated central necrosis of the tumor cells, and that the peripheral tumor cells were disorderly. Scale bar, $100 \mu \mathrm{m}$.
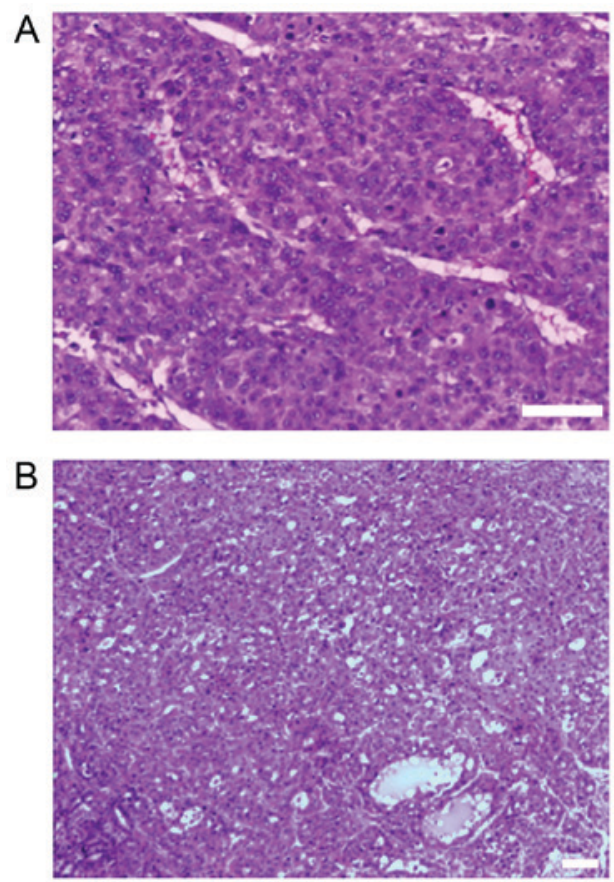

Figure 2. Morphological changes following RFA. Representative tumor cells stained with H\&E (A) prior to and (B) following RFA. Note that thermal coagulation gradually became white, and that the boundaries were less clear. Notable inflammatory cell infiltration was observed. H\&E, hematoxylin and eosin; RFA, radiofrequency ablation. Scale bar, $100 \mu \mathrm{m}$.

cells were less clear, indicating a clearance of tumor cells. Furthermore, inflammatory cell infiltration was observed in parts of the remaining tumor cells (Fig. 2B). 
RFA activates primary NK cells. RFA has been reported to induce inflammatory cell infiltration. Inflammation is associated with immune activity; therefore, the innate immune responses in the tumor cells were assessed. As one of the most abundant components of the innate immune system, NK cells account for $10-15 \%$ of peripheral blood lymphocytes, and are defined by the expression of CD56. Furthermore, the CD69 differentiation antigen is one of the earliest cell surface molecules expressed following NK cell activation; therefore, FACS was used to determine the NK cell proportion in the peripheral blood via calculation of the $\mathrm{CD} 56^{+} \mathrm{CD} 69^{+}$cell percentage. Compared with cells in the normal control rabbit, the $\mathrm{CD} 6^{+} \mathrm{CD} 69^{+} \mathrm{NK}$ cell number in the $\mathrm{VX} 2$ rabbit was significantly decreased $(\mathrm{P}<0.01)$, indicating the suppression of immune activity following tumor growth prior to RFA treatment. Following 1 week of RFA treatment, the NK cell number was increased $(\mathrm{P}<0.05)$, indicating a quick stimulation of the innate immune system. The percentage of $\mathrm{CD} 56^{+} \mathrm{CD} 69^{+}$ NK cells was continuously upregulated in the fourth week following RFA treatment (Fig. 3A).

As the major cytokines released by NK cells are IFN- $\gamma$ and TNF- $\alpha$, an ELISA assay was used to measure the levels of cytokines in the cell medium. Similar to the increase in the NK cell population, the IFN- $\gamma$ and TNF- $\alpha$ levels were also significantly elevated following RFA treatment in the VX2 animals. Their levels were the highest following the first week of RFA treatment and maintained through the fourth week after RFA treatment, indicating the innate immune system was induced and activated by RFA treatment (Fig. 3B and C).

RFA enhances NKG2D expression and NK cell function. NKG2D is the most important activating receptor present on the surface of NK cells. A variety of immune cell therapies in cancer treatments rely on the recognition of tumor targets via the expression of the NKG2D ligand. To explore whether NKG2D contributed to the enhanced immune activity following RFA treatment, the expression of NKG2D was examined using FACS analysis. It was identified that the NKG2D expression was notably low prior to RFA treatment; however, as depicted in Fig. 4A, NKG2D was markedly upregulated at one week following RFA treatment.

In order to further verify the role of NKG2D in enhancing the killing activity of NK cells, NK cells sorted from the VX2 model cells were co-cultured with human hepatoblastoma HepG 2 cells, and the neutralizing antibody against NKG2D was added to the co-culture. The in vitro killing assay demonstrated that a notable increase in killing activity was observed in NK cells with macrophages from RFA-treated animals, compared with NK cells with macrophages from non-treated animals. Blocking NKG2D using a specific antibody notably impaired the RFA-induced immune activity, as the NK cell-mediated killing activity was significantly downregulated (Fig. 4B). This confirmed that NKG2D is an important activating receptor in RFA-induced NK cell activation.

Perforin-mediated cytotoxicity and Fas ligand (FasL) dependent antitumor activity are important targets for NK cell therapy (39). The anti-metastatic activity following RFA treatment was assessed. As depicted in Fig. 4C and D, RFA treatment induced the notable upregulation of perforin and FasL expression, compared with the control NK cells from untreated animals, or the NK cells incubated with a control isotype antibody. In cells cultured with the NKG2D neutralizing antibody, the expression levels of the NK cell surface marker CD69 and the NK cell effectors perforin and FasL were significantly decreased. Taken in combination, these experiments demonstrated that RFA treatment could suppress tumor metastases, depending on the sensitivity of the tumor to perforin or FasL, and reduce the expression of NKG2D ligands.

\section{Discussion}

In the present study, it was demonstrated that RFA treatment could effectively eliminate liver tumors through enhancement of NK-mediated antitumor activity and NKG2D expression.

Curative resection has been considered to be the first choice therapeutic strategy for a number of malignant tumor types (40); however, only $20 \%$ of the patients with liver cancer are eligible for surgical resection due to cancer multifocality, including severe impairment of hepatic functional reserve, extrahepatic metastases, involvement of the portal vein and severe extrahepatic disease (7-9). To date, various treatment strategies for liver cancer, including local ablative therapies, transarterial embolization and liver transplantation, have been developed. RFA has gained widespread acceptance as a local ablative treatment option for patients, due to it being highly effective, minimally invasive and a generally safe therapy for primary and secondary hepatic malignancies $(10,11,14,41)$.

Via the heating of tumor tissue to temperatures exceeding $50^{\circ} \mathrm{C}$, RFA produces localized tumor coagulative necrosis, which results in the final destruction of the tumor tissues (21). Although the success rate for completely eliminating small liver tumors is $>85 \%$ with RFA, incomplete ablation frequently occurs and leads to tumor reoccurrence $(10,11,41)$. Depending on the patient's medical situation, the overall complete ablation rate ranges from $50-93 \%$. The tumor size is another risk factor, for tumors of diameter $\leq 3,3-5$ and $\geq 5 \mathrm{~cm}$, the complete ablation rate is $77-100,84-93.5$ and $41-71 \%$, respectively, following a single treatment session (41). Additionally, local recurrence following RFA limits its application, with a rate varying between 2-60\% (42). The tumor recurrence rate may be notably higher in a number of specific anatomical locations (43). In the present study, four weeks following thermal ablation the coagulation of the tumor had become white, and the boundary between the tumor and surrounding tissues remained undistinguishable, indicating complete ablation in the animal model. However, tumor recurrence should still be determined over a longer time period.

Innate and adaptive immune cells actively prevent cancer development (44). A notable inflammatory cell infiltration was observed following RFA, which led to speculation that the immune system was activated following RFA treatment. As one of the most important components of the innate immune system, NK cells serve critical roles in host immunity to cancer (45). NK cells have the ability to lyse certain tumor cells in the absence of prior stimulation (24). In response to tumor invasion, NK cells exert their function via two principal underlying mechanisms: i) Releasing cytoplasmic granules containing perforin and granzymes that lead to tumor-cell apoptosis; ii) secreting cytokines to modulate the functions of other immunocytes (22). The cytotoxic activity of NK cells 
A

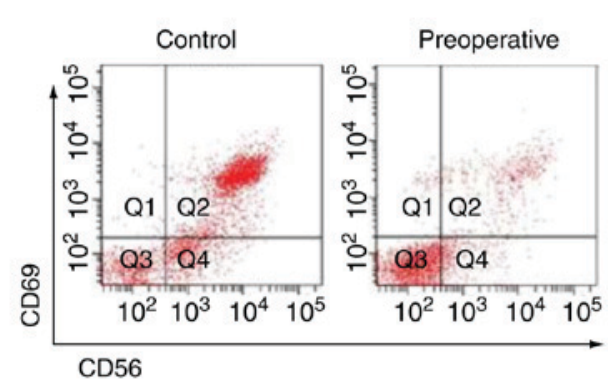

$\mathrm{B}$

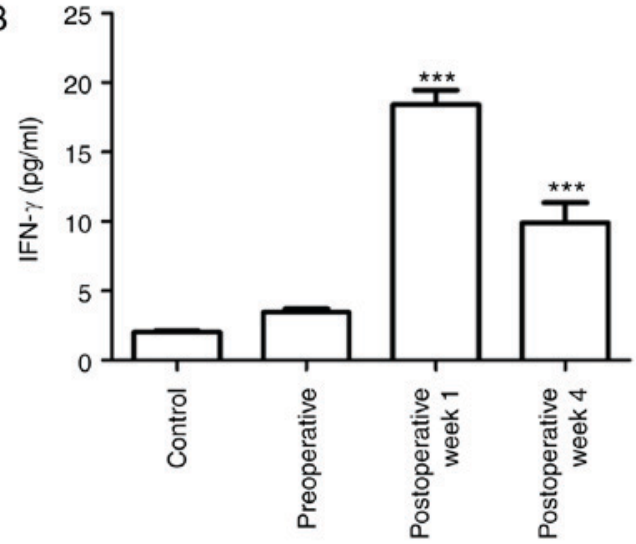

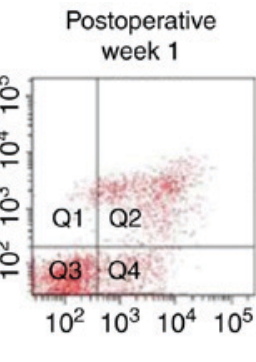

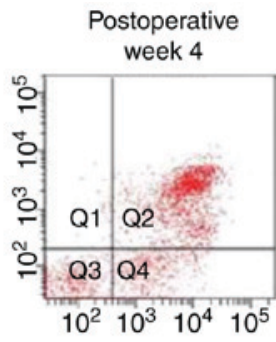

C

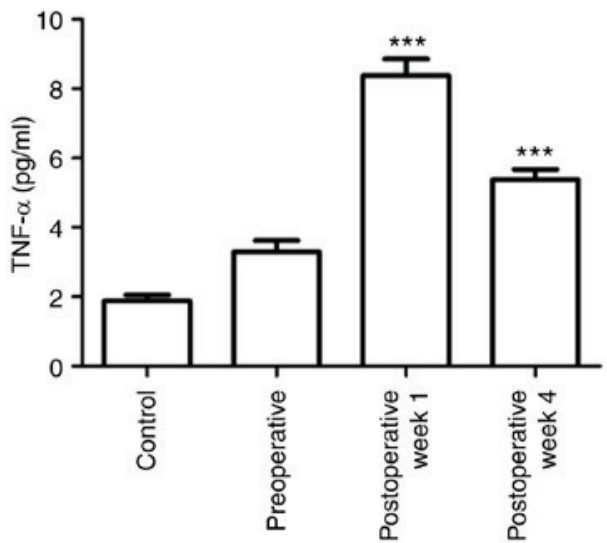

Figure 3. RFA activates primary NK cells. (A) The expression of CD69+ and CD56 $6^{+} \mathrm{NK}$ cells in the peripheral blood mononuclear cells of rabbit was analyzed via flow cytometry during the 4 weeks following RFA. Control groups were blood cells from untreated rabbits. (B and C) The secreted levels of IFN- $\gamma$ and TNF- $\alpha$ in the NK cells from the peripheral blood mononuclear cells in the rabbits were evaluated using an ELISA. ${ }^{* * *} \mathrm{P}<0.001$. Control groups included cells from untreated rabbits. IFN, interferon; TNF, tumor necrosis factor; NK, natural killer; RFA, radiofrequency ablation.
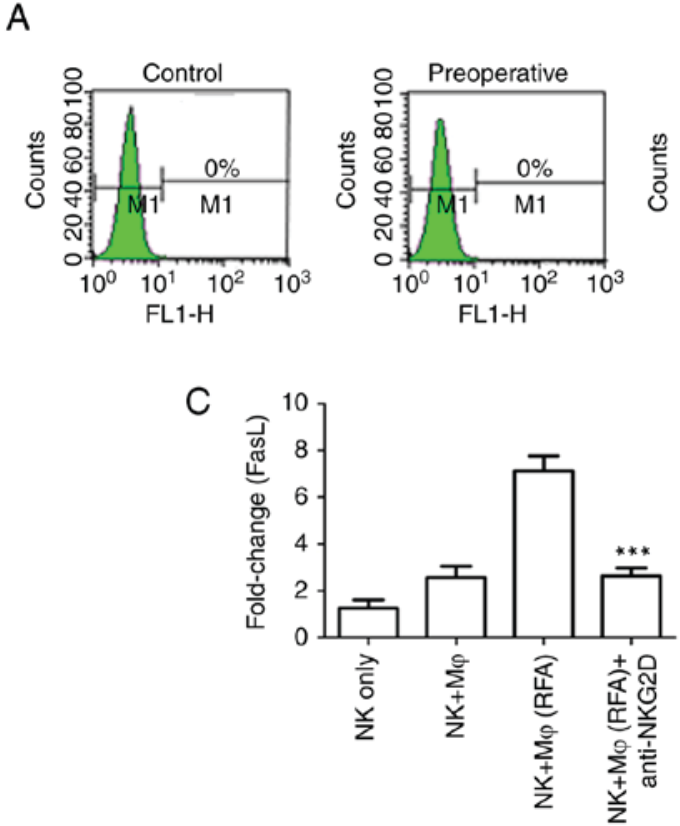
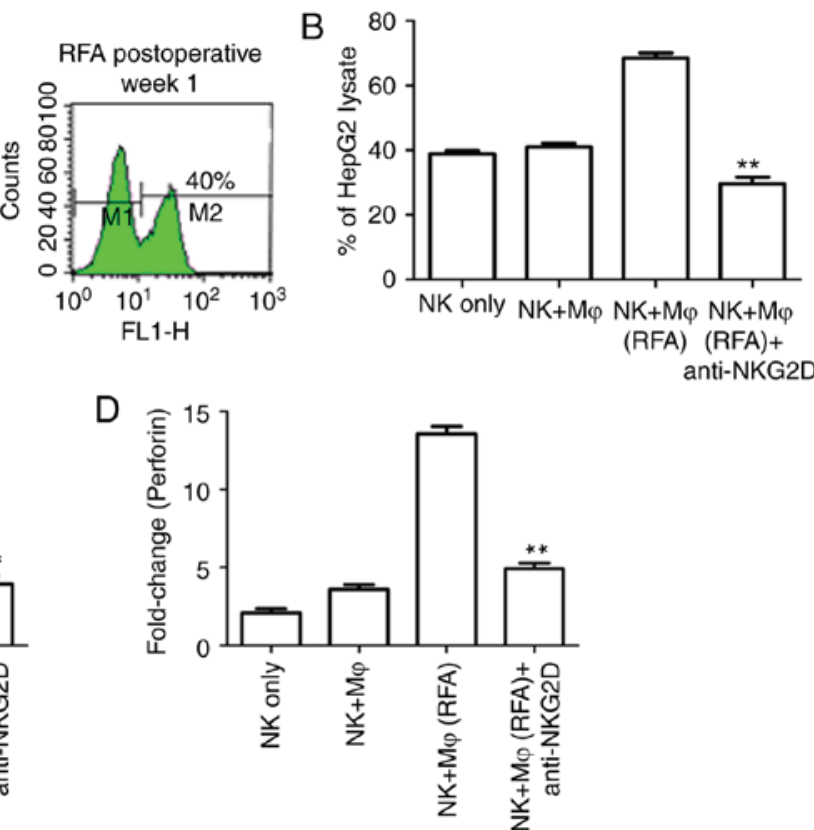

Figure 4. RFA enhanced NKG2D expression and NK cell function. (A) NKG2D expression in the control cells, pre-surgery cells and cells at 1 week following RFA treatment was determined via flow cytometry. The control group included cells from V2X rabbit tumors prior to RFA treatment. (B) The isolated NK cells co-cultured with HepG2 cells were incubated with anti-NKG2D or isotype control antibodies (with or without RFA treatment), and the cytotoxic effects were compared. (C and D) Cytotoxic effector molecules FasL and perforin were evaluated with an ELISA. ${ }^{* *} \mathrm{P}<0.01$ and ${ }^{* * * *} \mathrm{P}<0.001 \mathrm{vs}$. the NK and M $\phi(\mathrm{RFA})$ groups. NK, natural killer; FasL, Fas ligand; RFA, radiofrequency ablation; NKG2D, NK group 2D; M $\phi$.

is modulated by NK cell receptors and cytokines $(24,25)$. The results indicated that RPA activates primary NK cells and induces the stimulation of cytokines, including IFN- $\gamma$ and TNF- $\alpha$, in VX2 rabbit cells. Antibody neutralization demonstrated that the RFA-induced immune activation is dependent on the NK receptor NKG2D. RFA treatment also induced the elevation of the stimulatory receptor CD69 and effector molecules, including perforin and FasL; this indicates 
that RFA treatment induces antitumor mechanisms. It is important for the mechanisms underlying liver tumor control to be further characterized using a greater number and variety of in vivo models.

Collectively, the results indicated that the RFA treatment for liver cancer is a promising therapeutic strategy, and that RFA-induced immune activation serves an important role in suppressing cancer in animal models. While the present study mainly focused on liver cancer, further investigations should be conducted using other cancer types and in vivo models.

\section{Acknowledgements}

The authors would like to thank FL Zhao for assistance of the writing.

\section{Funding}

The present study was supported by the Natural Science Foundation of Hainan Province (grant no. 20158292).

\section{Availability of data and materials}

The datasets analyzed during the current study are available from the corresponding author on reasonable request.

\section{Author's contributions}

$\mathrm{ZM}$ and HL conceived this study and performed all these experiments. SM and XF helped with the VX2 model. SC and JY helped with the cell culture and data analysis. All authors read and approved the final manuscript.

\section{Ethics approval and consent to participate}

The animal experiments in the present study were carried out according to the guidelines on animal welfare and regulations of Hainan Province, China and were evaluated and approved by the Institutional Animal Care and Use Committee of Research Center for Drug Safety Evaluation of Hainan (HNYWAPZX201607011).

\section{Consent for publication}

Not applicable.

\section{Competing interests}

The authors declare that they have no competing interests.

\section{References}

1. Davis GL, Dempster J, Meler JD, Orr DW, Walberg MW, Brown B Berger BD, O'Connor JK and Goldstein RM: Hepatocellular carcinoma: Management of an increasingly common problem. Proc (Bayl Univ Med Cent) 21: 266-280, 2008.

2. Bosch FX, Ribes J, Díaz M and Cléries R: Primary liver cancer: Worldwide incidence and trends. Gastroenterology 127 (5 Suppl 1): S5-S16, 2004.

3. Simonetti RG, Camma C, Fiorello F, Politi F, D'Amico G and Pagliaro L: Hepatocellular carcinoma. A worldwide problem and the major risk factors. Dig Dis Sci 36: 962-972, 1991.
4. Chen W, Zheng R, Baade PD, Zhang S, Zeng H, Bray F, Jemal A, Yu XQ and He J: Cancer statistics in China, 2015. CA Cancer J Clin 66: 115-132, 2016.

5. Torre LA, Bray F, Siegel RL, Ferlay J, Lortet-Tieulent J and Jemal A: Global Cancer Statistics, 2012. CA Cancer J Clin 65: 87-108, 2015.

6. Zhou Y, Sui C, Li B, Yin Z, Tan Y, Yang J and Liu Z: Repeat hepatectomy for recurrent hepatocellular carcinoma: A local experience and a systematic review. World J Surg Oncol 8: 55, 2010.

7. Lee PH, Lin WJ, Tsang YM, Hu RH, Sheu JC, Lai MY, Hsu HC, May W and Lee CS: Clinical management of recurrent hepatocellular carcinoma. Ann Surg 222: 670-676, 1995.

8. Kanematsu T, Matsumata T, Takenaka K, Yoshida Y, Higashi H and Sugimachi K: Clinical management of recurrent hepatocellular carcinoma after primary resection. Br J Surg 75: 203-206, 1988.

9. Tsujita E, Yamashita Y, Takeishi K, Matsuyama A, Tsutsui S, Matsuda H, Toshima T, Taketomi A, Shirabe K, Ishida T and Maehara Y: Poor prognostic factors after repeat hepatectomy for recurrent hepatocellular carcinoma in the modern era. Am Surg 78: 419-425, 2012.

10. Ikeda K, Osaki Y, Nakanishi H, Nasu A, Kawamura Y, Jyoko K, Sano T, Sunagozaka H, Uchino K, Minami Y, et al: Recent progress in radiofrequency ablation therapy for hepatocellular carcinoma. Oncology 87 (Suppl 1): S73-S77, 2014.

11. Feng K and Ma KS: Value of radiofrequency ablation in the treatment of hepatocellular carcinoma. World J Gastroenterol 20: 5987-5998, 2014

12. Xu Q, Kobayashi S, Ye X and Meng X: Comparison of hepatic resection and radiofrequency ablation for small hepatocellular carcinoma: A meta-analysis of 16,103 patients. Sci Rep 4: 7252, 2014.

13. Khajanchee YS, Hammill CW, Cassera MA, Wolf RF and Hansen PD: Hepatic resection vs. minimally invasive radiofrequency ablation for the treatment of colorectal liver metastases a markov analysis. Arch Surg 146: 1416-1423, 2011.

14. Fu C, Liu N, Deng Q, Li X, Ma K and Bie P: Radiofrequency ablation vs. surgical resection on the treatment of patients with small hepatocellular carcinoma: A system review and meta-analysis of five randomized controlled trials. Hepatogastroenterology 61: 1722-1729, 2014.

15. Nguyen T, Hattery E and Khatri VP: Radiofrequency ablation and breast cancer: A review. Gland Surg 3: 128-135, 2014.

16. van der Ploeg IM, van Esser S, van den Bosch MA, Mali WP, van Diest PJ, Borel Rinkes IH and van Hillegersberg R: Radiofrequency ablation for breast cancer: A review of the literature. Eur J Surg Oncol 33: 673-677, 2007.

17. Hiraki T, Gobara H, Iguchi T, Fujiwara H, Matsui Y and Kanazawa S: Radiofrequency ablation as treatment for pulmonary metastasis of colorectal cancer. World J Gastroenterol 20: 988-996, 2014.

18. Fegrachi S, Besselink MG, van Santvoort HC, van Hillegersberg R and Molenaar IQ: Radiofrequency ablation for unresectable locally advanced pancreatic cancer: A systematic review. HPB (Oxford) 16: 119-123, 2014.

19. McGhana JP and Dodd GD: Radiofrequency ablation of the liver: Current status. AJR Am J Roentgenol 176: 3-16, 2001.

20. Navarra G, Bartolotta M, Scisca C and Barbera A: Ultrasoundguided radiofrequency-assisted segmental arterioportal vascular occlusion in laparoscopic segmental liver resection. Surg Endosc 22: 1724-1728, 2008.

21. Liu CH, Yu CY, Chang WC, Dai MS, Hsiao CW and Chou YC: Radiofrequency ablation of hepatic metastases: Factors influencing local tumor progression. Ann Surg Oncol 21: 3090-3095, 2014.

22. Waldhauer I and Steinle A: NK cells and cancer immunosurveillance. Oncogene 27: 5932-5943, 2008.

23. Morvan MG and Lanier LL: NK cells and cancer: You can teach innate cells new tricks. Nat Rev Cancer 16: 7-19, 2016.

24. Marcus A, Gowen BG, Thompson TW, Iannello A, Ardolino M, Deng W, Wang L, Shifrin N and Raulet DH: Recognition of tumors by the innate immune system and natural killer cells. Adv Immunol 122: 91-128, 2014.

25. Hagerling $\mathrm{C}$, Casbon AJ and Werb Z: Balancing the innate immune system in tumor development. Trends Cell Biol 25: 214-220, 2015.

26. Moretta A, Marcenaro E, Parolini S, Ferlazzo G and Moretta L: NK cells at the interface between innate and adaptive immunity. Cell Death Differ 15: 226-233, 2008. 
27. Vivier E, Raulet DH, Moretta A, Caligiuri MA, Zitvogel L, Lanier LL, Yokoyama WM and Ugolini S: Innate or adaptive immunity? The example of natural killer cells. Science 331: 44-49, 2011.

28. Vivier E, Nunès JA and Vély F: Natural killer cell signaling pathways. Science 306: 1517-1519, 2004.

29. Xuan XY, Zhang JF, Hu GM, Li QR, Liu PP and Du Y: Upregulated expression of NKG2D and its ligands give potential therapeutic targets for patients with thymoma. Cancer Gene Ther 22: 368-374, 2015.

30. Baragaño Raneros A, Suarez-Álvarez B and López-Larrea C: Secretory pathways generating immunosuppressive NKG2D ligands: New targets for therapeutic intervention. Oncoimmunology 3: e28497, 2014.

31. Spear P, Wu MR, Sentman ML and Sentman CL: NKG2D ligands as therapeutic targets. Cancer Immun 13: 8, 2013.

32. Dromi SA, Walsh MP, Herby S, Traughber B, Xie J, Sharma KV, Sekhar KP, Luk A, Liewehr DJ, Dreher MR, et al: Radiofrequency ablation induces antigen-presenting cell infiltration and amplification of weak tumor-induced immunity. Radiology 251: 58-66, 2009.

33. Zerbini A, Pilli M, Laccabue D, Pelosi G, Molinari A, Negri E, Cerioni S, Fagnoni F, Soliani P, Ferrari C and Missale G: Radiofrequency thermal ablation for hepatocellular carcinoma stimulates autologous NK-cell response. Gastroenterology 138: 1931-1942, 2010.

34. Virmani S, Harris KR, Szolc-Kowalska B, Paunesku T, Woloschak GE, Lee FT, Lewandowski RJ, Sato KT, Ryu RK, Salem R, et al: Comparison of two different methods for inoculating VX2 tumors in rabbit livers and hind limbs. J Vasc Interv Radiol 19: 931-936, 2008

35. Fischer AH, Jacobson KA, Rose J and Zeller R: Hematoxylin and eosin staining of tissue and cell sections. CSH Protoc 2008: pdb. prot4986, 2008.

36. Hoppner M, Luhm J, Schlenke P, Koritke P and Frohn C: A flow-cytometry based cytotoxicity assay using stained effector cells in combination with native target cells. J Immunol Methods 267: 157-163, 2002.
37. Livak KJ and Schmittgen TD: Analysis of relative gene expression data using real-time quantitative PCR and the 2(-Delta Delta C(T)) method. Methods 25: 402-408, 2001.

38. Seong NJ, Yoon CJ, Kang SG, Chung JW, Kim HC and Park JH: Effects of arsenic trioxide on radiofrequency ablation of VX2 liver tumor: Intraarterial versus intravenous administration. Korean J Radiol 13: 195-201, 2012.

39. Ohshima K, Suzumiya J, Shimazaki K, Kato A, Tanaka T, Kanda $M$ and Kikuchi $M$ : Nasal T/NK cell lymphomas commonly express perforin and Fas ligand: Important mediators of tissue damage. Histopathology 31: 444-450, 1997.

40. Scheele J, Stangl R and Altendorf-Hofmann A: Hepatic metastases from colorectal carcinoma: Impact of surgical resection on the natural history. Br J Surg 77: 1241-1246, 1990.

41. Cucchetti A, Piscaglia F, Cescon M, Ercolani G and Pinna AD: Systematic review of surgical resection vs. radiofrequency ablation for hepatocellular carcinoma. World J Gastroenterol 19: 4106-4118, 2013.

42. Mulier S, Ni Y, Jamart J, Ruers T, Marchal G and Michel L: Local recurrence after hepatic radiofrequency coagulation: Multivariate meta-analysis and review of contributing factors. Ann Surg 242: 158-171, 2005.

43. Pawlik TM, Izzo F, Cohen DS, Morris JS and Curley SA: Combined resection and radiofrequency ablation for advanced hepatic malignancies: Results in 172 patients. Ann Surg Oncol 10: 1059-1069, 2003.

44. Gajewski TF, Schreiber H and Fu YX: Innate and adaptive immune cells in the tumor microenvironment. Nat Immunol 14 : 1014-1022, 2013.

45. Cheng M, Chen Y, Xiao W, Sun R and Tian Z: NK cell-based immunotherapy for malignant diseases. Cell Mol Immunol 10: 230-252, 2013 .

This work is licensed under a Creative Commons Attribution-NonCommercial-NoDerivatives 4.0 International (CC BY-NC-ND 4.0) License. 